\title{
A Novel 6.14 Mb Duplication of Chromosome 8p21 in a Patient with Autism and Self Mutilation
}

\author{
Heval M. Ozgen - Wouter G. Staal · John C. Barber - Maretha V. de Jonge • \\ Marc J. Eleveld · Frits A. Beemer · Ron Hochstenbach · Martin Poot
}

Published online: 12 August 2008

(c) The Author(s) 2008

\begin{abstract}
Autism spectrum disorders (ASDs) are a group of neurodevelopmental disorders with a strong genetic etiology. Cytogenetic abnormalities have been detected in $5-10 \%$ of the patients with autism. In this study, we present the clinical, cytogenetic and array-comparative genomic hybridization (array-CGH) evaluation of a 13-year-old male with severe developmental delay, facial dysmorphic features, autism and self mutilation. The patient was found to carry a de novo duplication of chromosome region $8 \mathrm{p} 21$ of minimally 6.14 and maximally $6.58 \mathrm{Mb}$ as ascertained by bacterial artificial chromosome (BAC)-based arrayCGH. Hitherto, only a few patients with autism with cytogenetically visible duplications involving the chromosome 8 p21 region have been described, but the extent of these duplications has not been determined at the molecular level. This represents the smallest rearrangement of chromosomal region $8 \mathrm{p} 21$ as yet found in a patient with autism. For 11 of the 36 genes with known functions located within this duplication clear transcription in the brain was found.
\end{abstract}

H. M. Ozgen $(\bowtie) \cdot$ W. G. Staal · M. V. de Jonge

Department of Child and Adolescent Psychiatry, Rudolf Magnus Institute of Neuroscience, UMC Utrecht, HP B01.201, P.O. Box 85500, 3508, GA, Utrecht, The Netherlands

e-mail: h.m.ozgen@umcutrecht.nl

H. M. Ozgen - W. G. Staal - M. V. de Jonge

Rudolf Magnus Institute of Neuroscience, University Medical

Centre, Utrecht, The Netherlands

J. C. Barber

National Genetics Reference Laboratory (Wessex), Salisbury

Hospital NHS Trust, Salisbury, UK

M. J. Eleveld · F. A. Beemer · R. Hochstenbach · M. Poot Department of Medical Genetics, University Medical Centre, Utrecht, The Netherlands
Of those the STMN4 and DPYSL2 genes are the most likely candidate genes to be involved in neuronal development, and, if altered in gene-dosage, in the autistic phenotype of our patient.

Keywords Autism spectrum disorder . Array comparative genomic hybridization .

Developmental delay - Fluorescent in situ hybridization . Self mutilation $\cdot$ STMN4 $\cdot$ DPYSL2

\section{Introduction}

Autism spectrum disorders (ASDs) are complex neurodevelopmental disorders characterized by impaired social interaction and communication, accompanying restricted repetitive and stereotyped interests and behaviors presenting before three years of age. Autism is the most common among these disorders with current incidence estimates above 1 per 1,000 children and a male to female ratio of about 4:1 (Zhao et al. 2007). Approximately 70\% of individuals with autism show mental retardation (Schellenberg et al. 2006). Family and twin studies have demonstrated that autism has a strong heritable component, estimated to be at least $90 \%$ (Zhao et al. 2007). The concordance rate in monozygotic twins is $60-90 \%$, and the autism rate in siblings of the affected proband is $2-8 \%$, much higher than expected from the general population (Zhao et al. 2007).

Although linkage and association studies have indicated several different chromosomal regions, none of the approaches directly pinpointed autism susceptibility genes, and replication of findings has proven difficult in both research types (Yang and Gill 2007). Cytogenetic abnormalities, consisting of duplications, deletions, translocations, inversions and ring chromosomes have been detected in $5-10 \%$ of 
the patients with autism (Vorstman et al. 2006). Among the most frequently reported are abnormalities of chromosome 15, specifically the interval 15q11-q13 (Nurmi et al. 2003), $2 \mathrm{q} 37,5 \mathrm{p} 14-15$, several regions on chromosome $7,11 \mathrm{q} 25$, 16q22.3, 18q21.1, 18q23, 22q11.2, 22q13.3 and Xp22.2p22.3 (Vorstman et al. 2006). In addition, copy number variants (CNVs), ranging from a few kilobases to several megabases in size, have been detected in patients with autism (Jacquemont et al. 2006; Sebat et al. 2007; Hoyer et al. 2007; Marshall et al. 2008). Several candidate gene studies have been performed in patients with autism (Kalscheuer et al. 2007). Thus far, three reports on patients with autism and chromosome $8 \mathrm{p}$ duplications have been published (Kielinen et al. 2004; Demori et al. 2004; Papanikolaou et al. 2006). In these reports both the clinical diagnostic procedures and the precision of the molecular cytogenetic analyses are highly variable.

Here, we describe clinical and molecular cytogenetic findings in a patient with postnatal growth retardation, autism and self mutilation. Using GTG banding, fluorescence in situ hybridization (FISH) and bacterial artificial chromosome (BAC-based array comparative chromosome hybridization (array-CGH) we identified a $6.14 \mathrm{Mb}$ de novo duplication at band $8 \mathrm{p} 21.2-8 \mathrm{p} 21.3$ in our patient. This relatively small duplication allows us to identify several gene-dosage sensitive positional candidate genes for his phenotype.

\section{Methods}

\section{Clinical Report}

The patient (Fig. 1) was born at term after an uneventful pregnancy and delivery as the second child of healthy and non-consanguineous parents of Dutch Caucasian ancestry. His female sib was healthy and his family history was negative. His length was $52 \mathrm{~cm}$ (just above 50th centile), weight $3,900 \mathrm{~g}$ (97th centile). The postnatal period was characterized by feeding problems, constipation and recurrent upper respiratory tract infections with fever.

At 17 months of age he was referred for the first time. He showed retarded somatic development. His length at that time was below the 1 st centile, his weight below the $3 \mathrm{rd}$ centile and his skull circumference was at the 0.5 centile.

He first sat at 24 months. Speech development was severely delayed; he spoke his first words at 24 months. At 4 years of age cognitive and motor development were markedly retarded such that he was not yet able to walk without support. During early development, a number of ritualistic behaviors, self-injury and temper tantrums were observed.

On referral at the age of 13 years, he did not speak and his developmental level was at 15-18 months as measured with the Vineland Adaptive Behavior Scales. He was now able to walk independently. He showed stereotypic movements and behaviors and he suffered from self mutilation. His eye contact was limited and almost no reciprocal social interaction was reported. He had no interest in playing with other children, poor imaginative play, and limited responsiveness to social overtures. He was attending a school for children with special needs.

The accepted standard for autism diagnosis, the Autism Diagnostic Interview-Revised (ADI-R) (Lord et al. 1994) and Autism Diagnostic Observation Schedule-Generic (ADOS-G) instruments (Lord et al. 2000) were administered to confirm his previously determined clinical diagnosis of autism. The ADI-R score for social domain was 15 (cut-off $=10$ ), for the communication domain was 10 (cut-off $=8$ ), for stereotyped behaviors was 5 (cutoff $=3$ ) and for age of onset development was 5 (cutoff $=1$ ). This resulted in an ADI-R classification diagnosis of autism. He met ADOS criteria for autism with the scores of 8 for communication (autism cut-off $=4$ ), 14 for reciprocal social interaction (autism cut-off $=7$ ) and 22 for communication and social interaction total score (autism cut-off $=12$ ). Verbal and non-verbal communication were markedly limited and not used for the purpose of
Fig. 1 Frontal (a) and right lateral (b) craniofacial views of the patient at the age of 13 years. Note: asymmetry of the face with mild frontal bossing, deep-set eyes, upslanting palpebral fissures, prominent nose with a high bridge, short philtrum, large mouth with thick lips and downturned corners, and micrognathia
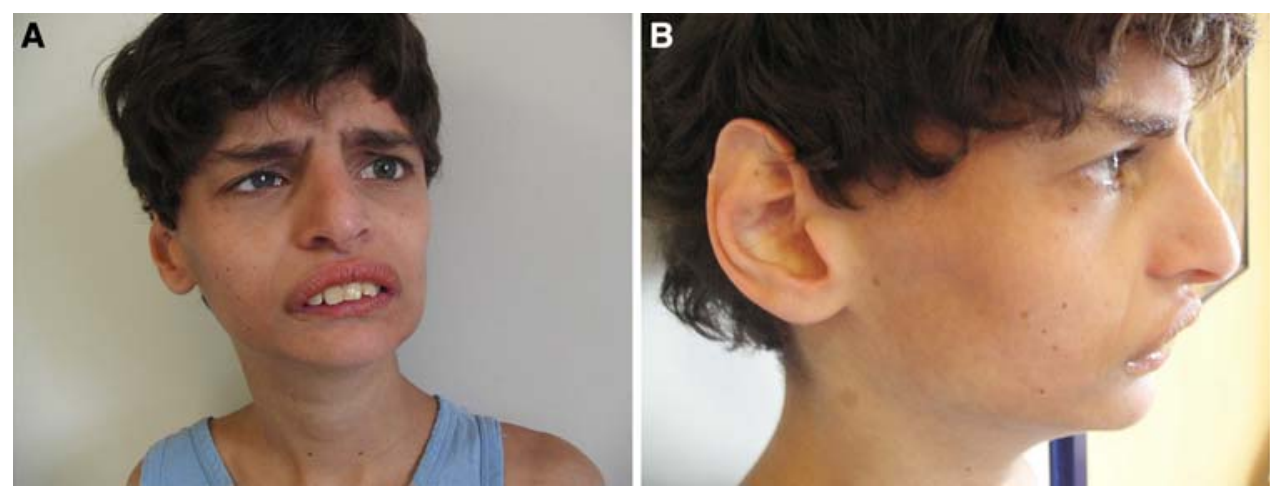
requesting. He did use some stereotyped phrases during the assessment and occasionally responded by nodding or shaking his head. There were stereotyped movements and behaviors.

Psychometric assessment with the Dutch version of the Psycho-Educational Profile-Revised (Schopler et al. 1990) showed that the patient is currently functioning at a developmental level of 17 months. This was confirmed by the results of the Vineland Adaptive Behavior Scales which placed him at a developmental level of 18 months (Sparrow et al. 1984). Because of the developmental level and the fact that speech was absent on referral, it would be unlikely that a reliable IQ measure could be obtained. Also, we felt that full IQ testing would be to demanding for this severely impaired patient.

Minor physical dysmorphic features included asymmetry of the face with mild frontal bossing, synorphis, deep-set eyes, upslanting palpebral fissures, prominent nose with a high bridge, short philtrum, large mouth with thick lips and down-turned corners, micrognathia, dysplactic ears and cataract (Fig. 1). The ear helices were flat with prominent antihelices and hypoplastic, attached, ear lobules. He had a slender trunk with wide-spaced nipples. His large joints were mildly hypermobile and he showed clinodactyly of the fifth fingers. In addition, he had a dry skin with a number of small café-au-lait patches. He had no tics or seizures.

Brain magnetic resonance imaging (MRI), electroencephalogram (EEG), routine blood and urine metabolic screening were normal as was endocrine function. A recent ophthalmologic investigation revealed retinal detachment, which may be resulting from self mutilation, and a mature cataract likely to be secondary to the retinal detachment.

Karyotyping revealed an additional Giemsa-dark band in 8p21 (Fig. 2).

\section{Cytogenetic and Fluorescence in situ Hybridization} (FISH) Studies

Short term lymphocyte cultures from peripheral blood were prepared following standard procedures. Metaphases were analyzed with GTG-banding at the 700 band level (as determined by the ISCN 2005 standards). Fluorescence in situ hybridization (FISH) was performed on metaphase and interphase chromosomes according to standard methods (Liehr and Claussen 2002), except that after hybridization, formamide was omitted from the washing buffer and slides were washed twice in $0.4 \times \mathrm{SSC} / 0.05 \%$ Tween- 20 at $72^{\circ} \mathrm{C}$ for $5 \mathrm{~min}$, followed by washes in $2 \times$ SSC $/ 0.05 \%$ Tween-20 and $4 \times$ SSC/0.05\% Tween- 20 at room temperature for $5 \mathrm{~min}$ each. BAC probes from the short arm of chromosome 8 were obtained from the Wellcome Trust Sanger Institute, Cambridge, United Kingdom. These were RP11-158F9 (from nucleotide $24,892,795$ to $24,893,364$ in $8 \mathrm{p} 21.2$ ), RP11-138J2 (from nucleotide $27,277,246$ to $27,462,612$ in 8 p21.2-p21.1) and RP11-275K7 (from nucleotide 28,922,993 to $28,923,242$ in
Fig. 2 Partial karyotypes and idiogram of the normal and duplicated chromosomes 8 of our patient. Panel (a) shows an idiogram depicting the duplication of (8)(p12p21.3); Panels (b, c) depict the normal (left hand) and the aberrant (right hand) chromosome 8 of our patient; the arrowheads indicate the likely positions of the breakpoints. Panel (d) shows FISH with probe RP11-158F9; note the difference in intensity between the normal (Left hand) and the aberrant (right hand) homologue. Panel (e) depicts an interphase nucleus hybridized with RP11-158F9 (green) and with RP11-138J2 (red). The aberrant chromosome (left) shows a sequence of green-redgreen-red spots reflecting a direct orientation of the duplication

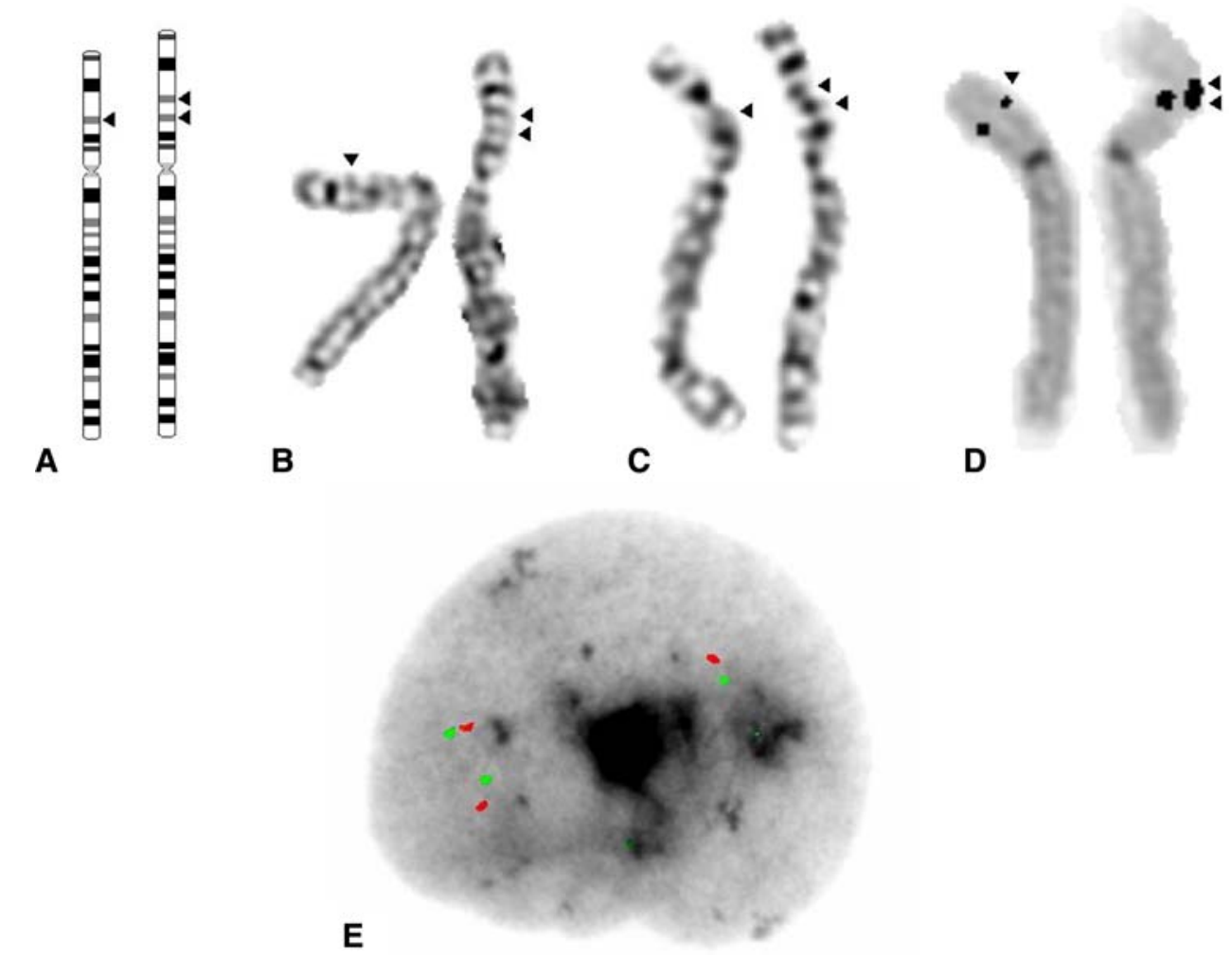


8p21.1-p12). Probe positions are according to March 2006 human reference sequence (NCBI Build 36.1).

Array-Based Comparative Genomic Hybridization

For segmental aneuploidy profiling by Array-CGH 1 microgram of sonicated genomic DNA from our patient (Tester) and 1 microgram of sonicated genomic DNA from a pool of 50 healthy male individuals (Reference) were labelled using the BioPrime DNA Labeling System (Invitrogen, Carlsbad, CA) with Cy3-dUTP and Cy5-dUTP (Amersham Biosciences, Little Chalfont, UK), respectively. These labelled DNAs were hybridized to the arrayslides using a GeneTAC Hybstation (Genomic Solutions, Ann Harbor, MI). The array has been created by spotting in triplicate DOP-PCR products of 3,783 BAC DNA probes, which have been chromosomally localized using FISH, and cover the entire human genome with a spacing of approximately $1 \mathrm{Mb}$ (Vissers et al. 2003). After hybridization the slides were scanned and imaged on a ScanArray Express HT (Perkin Elmer, Wellesley, MA) using the ScanArray Express software (version 2.1). Data were analyzed with the GenePix Pro 5.0 software package (Axon Instruments, Union City,CA) followed by LOWESS normalization using the Acuity 3.1 software package (Axon Instruments, Union City,CA). After analysis the averages of all triplicates were calculated. Signals with a standard deviation above 0.3 were excluded. The fluorescence ratios of all autosomes excluding chromosome 8 covered a $95 \%$ confidence interval of $10.6 \%$. Therefore, thresholds for copy number gain and loss were set at ${ }^{2} \log$ Patient/Reference values of +0.106 and -0.106 , respectively.

\section{Results}

Molecular Cytogenetic Investigation

Genome wide segmental aneuploidy profiling by Array CGH detected no aberrations of chromosome 4 and 17. Therefore, the Wolf-Hirschhorn and Smith-Magenis syndromes were excluded. Combining data from FISH experiments and Array-CGH showed a segmental trisomy of minimally 6.14 and maximally $6.58 \mathrm{Mb}$ in chromosome $8 \mathrm{p} 21$ (Fig. 3). The distal breakpoint was located within the $6.5 \mathrm{~kb}$ between BAC probes RP11-274M9 (from nucleotide position $22,610,552$ to $22,772,522$ ) and RP11-89M8 (from nucleotide position $22,779,190$ to $22,950,509$ ). The proximal breakpoint was located within the $430 \mathrm{~kb}$ between BAC probes RP11-275K7 (from nucleotide position 28,922,993 and $28,923,242$ ) and RP11-5J20 [from nucleotide position 29,353,235 to 29,507,616; March 2006 human reference sequence (NCBI Build 36.1)]. FISH using the RP11-158F9 BAC probe revealed a difference in signal intensity on metaphase chromosomes (Fig. 2d), thereby confirming the Array CGH result. In order to determine the orientation of the
Fig. 3 Segmental aneuploidy profile by array $\mathrm{CGH}$ of chromosome 8 of our patient. Microarray analysis of the patient demonstrated duplication of the short arm of chromosome 8 . The abscissa shows probes sorted according to their chromosomal position, and the ordinate shows to ${ }^{2} \mathrm{Log}$ fluorescence ratios and standard deviation for each individual probe of patient versus reference DNA. The horizontal bar demarcates the duplicated region; the vertical blue dotted line indicates the position of the centromere of chromosome 8

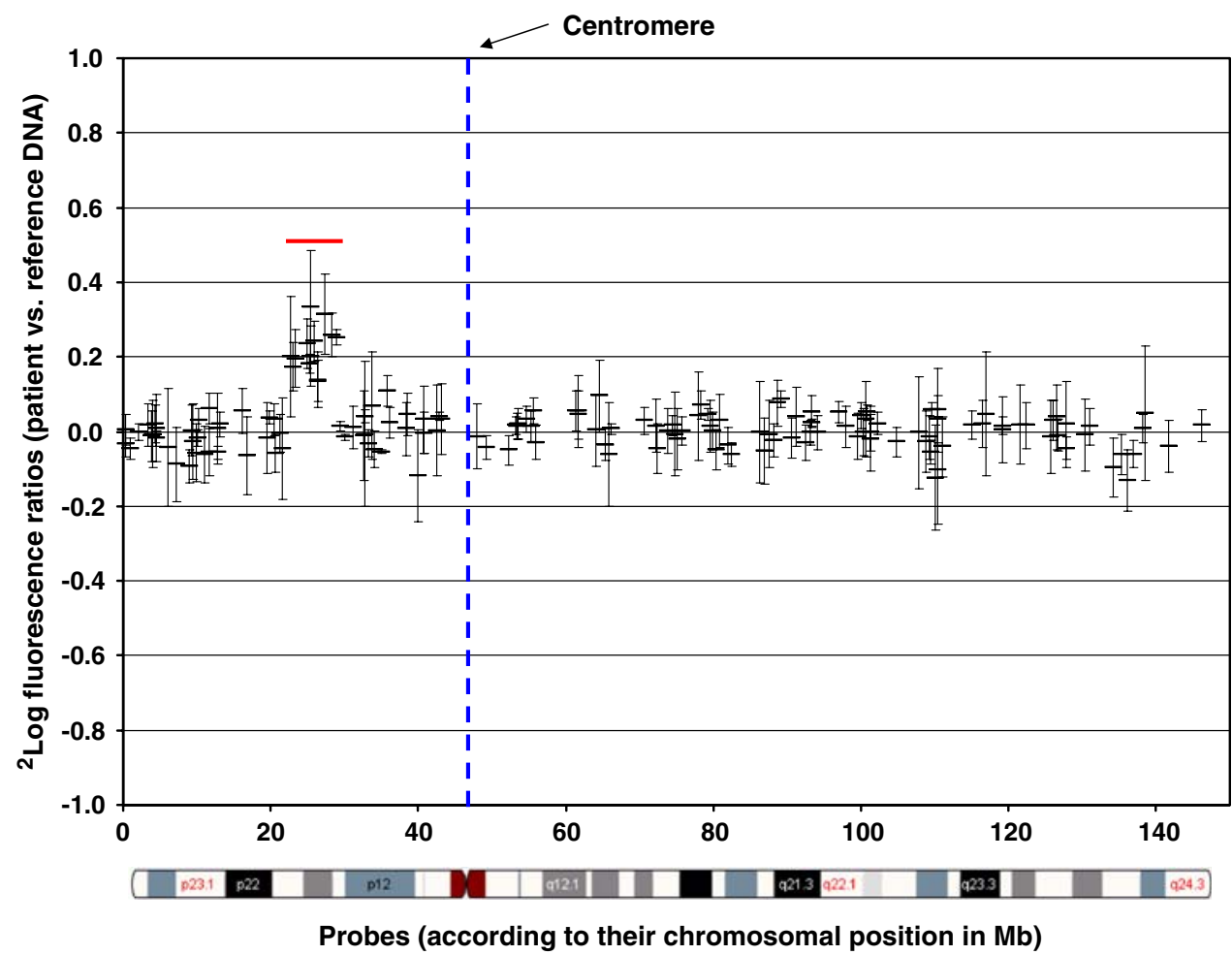


Table 1 Genes with transcript expression the central nervous system located within the maximally duplicated region of chromosome 8 of our patient

\begin{tabular}{|c|c|c|c|}
\hline Gene ID & Protein name & OMIM & Expression and function \\
\hline RHOBTB2 & $\begin{array}{l}\text { Rho-related BTB domain } \\
\text { containing } 2\end{array}$ & 607352 & $\begin{array}{l}\text { Highly expressed in neural tissues; also in fetal lung, heart, and brain. Functions as a } \\
\text { tumor suppressor, with roles in cell cycle and apoptosis }\end{array}$ \\
\hline$M S C P$ & $\begin{array}{l}\text { Mitoch solute carrier } \\
\quad(\text { SLC25A37) }\end{array}$ & 610387 & $\begin{array}{l}\text { Highly expressed in the CNS. Functions as calcium-dependent mitochondrial solute } \\
\text { carrier. }\end{array}$ \\
\hline$N E F 3$ & $\begin{array}{l}\text { Neurofilament } 3(150 \mathrm{kDa} \\
\text { medium) }\end{array}$ & 162250 & $\begin{array}{l}\text { Highly expressed in the entire brain (Dentate gyrus, hippocampal region, main olfactory } \\
\text { bulb). Primarily associated with dopamine D1 receptor function. }\end{array}$ \\
\hline PNMA2 & $\begin{array}{r}\text { Paraneoplastic antigen Ma2 } \\
\text { (Onconeuronal Ag MA2) }\end{array}$ & 603970 & $\begin{array}{l}\text { Highly expressed in entire brain and ileum A 'brain-testis-cancer' gene related to other } \\
\text { neoplastic syndromes and tumors }\end{array}$ \\
\hline DPYSL2 & $\begin{array}{l}\text { DPYLS2: Dihydropyrimidinase- } \\
\text { like } 2\end{array}$ & 602463 & Highly expressed in the fetal and the adult CNS. Regulates axonal growth and branching \\
\hline$A D R A 1 A$ & Alpha-1A adrenergic receptor & 104221 & $\begin{array}{l}\text { Highly expressed in the cerebellar peduncles; esp in the limbic brain and prefrontal } \\
\text { cortex.May contribute to cognitive functions relevant to schizophrenia }\end{array}$ \\
\hline STMN4 & Stathmin-like 4 & & $\begin{array}{l}\text { Highly expressed in the fetal and the adult Plays an important role in the regulation of } \\
\text { the microtubule cytoskeleton }\end{array}$ \\
\hline$P T K 2 B$ & $\begin{array}{l}\text { PTK2B protein tyrosine kinase } \\
2 \text { beta }\end{array}$ & 601212 & $\begin{array}{l}\text { Most abundant in the brain, with highest levels in amygdala and hippocampus. Involved } \\
\text { in calcium induced regulation of ion channel and activation of the map kinase } \\
\text { signaling pathway. May represent an important signaling intermediate between } \\
\text { neuropeptide activated receptors or neurotransmitters that increase calcium flux and } \\
\text { the downstream signals that regulate neuronal activity. Interacts with the SH2 domain } \\
\text { of Grb2. May phosphorylate the voltage-gated potassium channel protein Kv1.2 }\end{array}$ \\
\hline CHRNA2 & $\begin{array}{l}\text { Cholinergic receptor, nicotinic, } \\
\text { alpha polypeptide } 2\end{array}$ & 118502 & $\begin{array}{l}\text { Highly expressed in the thalamus and the kidney. Neuronal acetylcholine receptor } \\
\text { protein, alpha- } 2 \text { chain precursor. After binding acetylcholine, the AChR responds by } \\
\text { an extensive change in conformation that affects all subunits and leads to opening of } \\
\text { an ion-conducting channel across the plasma membrane. Defects in CHRNA2 are the } \\
\text { cause of autosomal dominant nocturnal frontal lobe epilepsy type } 4 \text { (ENFL4) }\end{array}$ \\
\hline$P N O C$ & Prepronociceptin & 601459 & $\begin{array}{l}\text { Transcripts expressed predominantly in the brain and spinal cord.receptor (OPRL1). } \\
\text { Nociceptin is the ligand of the opioid receptor-like It may act as a transmitter in the } \\
\text { brain by modulating nociceptive anxiety, cognition and locomotor behavior. May be } \\
\text { involved in neuronal differentiation and development }\end{array}$ \\
\hline FZD3 & $\begin{array}{l}\text { Frizzled homolog } 3 \\
\quad \text { (Drosophila) }\end{array}$ & 606143 & $\begin{array}{l}\text { Relatively highly expressed in the CNS, including regions of the limbic system. } \\
\text { Receptor for Wnt proteins. Most of frizzled receptors are coupled to the beta-catenin } \\
\text { canonical signaling pathway, which leads to the activation of dishevelled } \\
\text { proteins,inhibition of GSK-3 kinase, nuclear accumulation of beta-catenin and } \\
\text { activation of Wnt target genes. May be involved in transduction and intercellular } \\
\text { transmission of polarity information during tissue morphogenesis and/or in } \\
\text { differentiated tissues }\end{array}$ \\
\hline
\end{tabular}

duplication we performed FISH with combinations of either RP11-158F9 or RP11-138J2 (each labeled with biotin) with RP11-275K7 (labeled with digoxigenin). For both probe combinations, the arrangement of red and green signal spots in interphase nuclei was consistent with a direct orientation of the duplication (Fig. 2e). The karyotype of our patient was determined to be 46,XY, dir $\operatorname{dup}(8)(\mathrm{p} 21.1 \mathrm{p} 21.3)$.ish dir dup(8)(RP11-158F9++).nuc ish dir dup(8)(RP11-158F9+, RP11-138J2+,RP11-158F9+,RP11-138J2+).arr cgh 8p21. 1p21.3(RP11-89M8->RP11-275K7)x3. The duplication was de novo, as both parents had a normal karyotype and normal results using Array-CGH. In the duplicated region 36 genes with known function and 41 hypothetical genes and gene fragments have been located [Human Genome Browser, UCSC, March 2006 human reference sequence (NCBI Build
36.1)]. Table 1 lists genes showing clear transcript expression in the central nervous system.

\section{Discussion}

Diagnosing autism in children with a very low developmental age is challenging. The ADI-R, although widely used in research, is not well validated for diagnosis in children with developmental ages below 24 months. According to the ADI-R manual, the instrument can to some extent be used in children with mental ages below 24 months (Rutter et al. 2003). In addition a recent study by Gotham et al. (2007) shows that the module 1 version of the ADOS, as used in this case, is appropriate in children 
with a mental age $<15$ months. In very young or lowfunctioning children, who are not able to use meaningful words, but with non-verbal mental ages of $>15$ months (as in our case) sensitivity and specificity of the ADOS classification is high: 97 and 91, respectively (Gotham et al. 2007). These findings support previous reports regarding the validity of the ADOS in children with profound mental retardation (Berument et al. 2005; de Bildt et al. 2004).

Patients with ASD often carry cytogenetically detectable abnormalities (Vorstman et al. 2006). Classical karyotyping and array-based genome-wide aneuploidy profiling revealed an extreme genetic heterogeneity in both syndromic and non-syndromic autism patients (Jacquemont et al. 2006; Sebat et al. 2007; Hoyer et al. 2007; Marshall et al. 2008). In particular, Jacquemont et al. (2006) found 9 different imbalances in 29 patients with syndromic autism, only one of which corresponded to a known autism susceptibility locus. In addition, Sebat et al. 2007 found distinct gains and losses in another 17 patients. Marshall et al. (2008) discovered 277 unbalanced CNVs in $44 \%$ of their ASD families, which were not present in 500 controls. None of these 26 imbalances or de novo copy number variants involved 8p21.3.

Here we report clinical and molecular cytogenetic findings of a male patient with delayed psychomotor development, facial dysmorphic features, autism and self mutilation. Our patient showed the smallest 8p21 microduplication so far reported. The molecular cytogenetic aberrations underlying these syndromes have specifically been excluded by our array-CGH data. The latter method did reveal a segmental trisomy of minimally 6.14 and maximally $6.58 \mathrm{Mb}$ in chromosome $8 \mathrm{p} 21$, however. Recently, autism has been associated with partial trisomy of 8p21-8p23 (Kielinen et al. 2004; Demori et al. 2004; Papanikolaou et al. 2006). The non-specific facial dysmorphic findings in our patient were not found in any of the described cases with duplications of part of chromosome 8p (Kielinen et al. 2004; Demori et al. 2004; Papanikolaou et al. 2006). Although the patient reported by Papanikolaou et al. (2006) has received a thorough psychiatric evaluation, the molecular cytogenetic analyses reported in these three studies are not precise enough to permit identification of possible positional candidate genes for autism.

Several studies have identified numerous candidate genes for ASD (Persico and Bourgeron 2006). Thus far, alterations in genes involved in pathways such as chromatin remodeling and gene regulation, cytoskeleton dynamics and synaptic scaffolding, cell adhesion, secondmessenger systems, and genes encoding secreted proteins, receptors and transporters have been associated with ASD (Persico and Bourgeron 2006). This by no means excludes the possibility that other genetic pathways may be involved in ASD. Yet, all genes of relevance to ASD share expression in the central nervous system as a common feature. Therefore, out of the 36 genes with known function in the duplicated region in our patient we consider those which show clear transcript expression in the central nervous system and with apparent functions in the pathways mentioned (Persico and Bourgeron 2006) as primary candidates for ASD. Based on this criterion the genes encoding stathmin 4 (STMN4) and dihydropyrimidinase-like 2 (DPYSL2) represent the most plausible gene-dosage sensitive candidate genes for development of ASD in our patient. No polymorphisms or pathogenic aberration similar to the duplication in our patient have been found (http://projects.tcag.ca). We also did not find any evidence for protein-protein interactions with proteins previously implicated in autism (http://string.embl.de/).

The NEF3 gene encodes a transcription factor which shows strong expression in the hippocampal region, the dentate gyrus and the olfactory bulb where this protein undergoes O-glycosylation of its tail domain (Lüdemann et al. 2005). Although NEF3 has been identified as a potential risk factor for neurodegenerative disorders (e.g. amyotrophic lateral sclerosis) this gene has never before been implicated in ASD or related neurodevelopmental disorders (Lüdemann et al. 2005).

Defects in the neuronal acetylcholine receptor subunit alpha-2 polypeptide (CHRNA2) are the cause of autosomal dominant nocturnal frontal lobe epilepsy type 4 (ENFL4) (MIM: 610353). Autosomal dominant frontal lobe epilepsy is characterized by nocturnal seizures with hyperkinetic automatisms and poorly organized stereotyped movements. None of these features were found in our patient or in his family. At this point it is unclear whether or how a duplication of this gene might contribute to the severe autism spectrum disorder, including self-mutilation in our patient.

The STMN4 protein is able to sequester and to interact directly with microtubules, thus causing a switch of tubulin from its straight conformation to a curved one (Holmfeldt et al. 2003; Ravelli et al. 2004). These changes correlate with the loss of lateral contacts and may lead to rapid microtubule depolymerization (Ravelli et al. 2004). Thus, altered gene dosage and consequential elevated expression levels of STMN4 may interfere with cytoskeleton dynamics and synaptic scaffolding, a pathway related to ASD (Lüdemann et al. 2005).

DPYSL2 plays an important role in axonal formation and pathfinding of growing axons to reach their target during brain development. DPYSL2 participates in breakdown of pyrimidines. DPYSL2 shares this feature with HGPRT, the gene involved in the self mutilation disorder Lesch-Nyhan syndrome (OMIM: 300322). Therefore, we hypothesize that dysfunction of DPYSL2 may contribute to the self mutilation phenotype of our patient (Myers et al. 2007). 
No specific information relating to brain development or any psychiatric disorder exists for the other brain-expressed genes, Rho-related BTB (RHOBTB2), the mitochondrial solute carrier SLC25A37 (MSCP), paraneoplastic antigen Ma2 (onconeuronal Ag MA2) (AB020690), Adrenergic receptor a-1a $(A D R A 1 A), \mathrm{PTK} 2 \mathrm{~B}$ protein tyrosine kinase 2 b $(P T K 2 B)$, prepronociceptin $(P N A O C)$ and the frizzled homolog 3 (FZD3) contained within the duplicated region in our patient. Therefore, STMN4 and DPYSL2, are the most likely candidate genes to be involved in neuronal development. As found in our patient altered dosage of these genes may be involved in ASD.

In summary, we report here on a boy with postnatal growth retardation and autism who carries a de novo duplication at $8 \mathrm{p} 21.2 \mathrm{p} 21.3$ of minimally 6.14 and maximally $6.58 \mathrm{Mb}$. To the best of our knowledge our patient represents the first case in which autism has been associated with a duplication in 8p21.3 mapped at the molecular level. This proved to be valuable in pinpointing disease genes, thus improving our understanding of genotypephenotype correlations. This report highlights both the diagnostic value of Array-CGH in children with complex clinical phenotypes and emphasizes the usefulness of the thus generated precise molecular cytogenetic information for identifying candidate genes for ASD and other neurodevelopmental disorders. Screening of larger population of patients with autism together with healthy controls, as well as functional studies and resequencing of the STMN4 and DPYSL genes, may aid to elucidate the possible involvement of these genes in autism.

Acknowledgments We gratefully acknowledge the patient and his parents for giving their consent to publish clinical data and photos. We thank Ing. Jarg van Asch for help in preparation of the figures.

Open Access This article is distributed under the terms of the Creative Commons Attribution Noncommercial License which permits any noncommercial use, distribution, and reproduction in any medium, provided the original author(s) and source are credited.

\section{References}

Berument, S. K., Starr, E., Pickles, A., Papanikolauou, K., Lord, C., et al. (2005). Pre-linguistic autism diagnostic observation schedule adapted for older individuals with severe to profound mental retardation: a pilot study. Journal of Autism and Developmental Disorders, 35(6), 821-829. doi:10.1007/s10803005-0027-4.

de Bildt, A., Sytema, S., Ketelaars, C., Kraijer, D., Mulder, E., Volkmar, F., et al. (2004). Interrelationship between autism diagnostic observation schedule-generic (ADOS-G), autism diagnostic interview-revised (ADI-R), and the diagnostic and statistical manual of mental disorders (DSM-IV-TR) classification in children and adolescents with mental retardation. Journal of Autism and Developmental Disorders, 34(2), 129-137. doi: 10.1023/B:JADD.0000022604.22374.5f.
Demori, E., Devescovi, R., Benussi, D. G., Dolce, S., Carrozzi, M., Villa, N., et al. (2004). Supernumerary ring chromosome 8: Clinical and molecular cytogenetic characterization in a case report. American Journal of Medical Genetics. Part A, 130(3), 288-294.

Gotham, K., Risi, S., Pickles, A., \& Lord, C. (2007). The autism diagnostic observation schedule: Revised algorithms for improved diagnostic validity. Journal of Autism and Developmental Disorders, 37(4), 613-627. doi:10.1007/s10803-006-0280-1.

Holmfeldt, P., Brannstrom, K., Stenmark, S., \& Gullberg, M. (2003). Deciphering the cellular functions of the Op18/Stathmin family of microtubule-regulators by plasma membrane-targeted localization. Molecular Biology of the Cell, 14(9), 3716-3729. doi: 10.1091/mbc.E03-03-0126.

Hoyer, J., Dreweke, A., Becker, C., Gohring, I., Thiel, C. T., Peippo, M. M., et al. (2007). Molecular karyotyping in patients with mental retardation using $100 \mathrm{~K}$ single-nucleotide polymorphism arrays. Journal of Medical Genetics, 44(10), 629-636. doi:10.1136/ jmg.2007.050914.

Jacquemont, M. L., Sanlaville, D., Raoul, O., Cormier-Daire, V., Lyonnet, S., et al. (2006). Array-based comparative genomic hybridisation identifies high frequency of cryptic chromosomal rearrangements in patients with syndromic autism spectrum disorders. Journal of Medical Genetics, 43(11), 843-849. doi: 10.1136/jmg.2006.043166.

Kalscheuer, V. M., FitzPatrick, D., Tommerup, N., Bugge, M., Niebuhr, E., Neumann, L. M., et al. (2007). Mutations in autism susceptibility candidate 2 (AUTS2) in patients with mental retardation. Human Genetics, 121(3-4), 501-509. doi:10.1007/ s00439-006-0284-0.

Kielinen, M., Rantala, H., Timonen, E., Linna, S. L., \& Moilanen, I. (2004). Associated medical disorders and disabilities in children with autistic disorder: a population-based study. Autism, 8(1), 49-60. doi:10.1177/1362361304040638.

Liehr, T., \& Claussen, U. (2002). FISH on chromosome preparations of peripheral blood. In B. Rautenstrauss \& T. Liehr (Eds.), FISH technology (pp. 73-81). Berlin: Springer.

Lord, C., Risi, S., Lambrecht, L., Cook, E. H., Leventhal, B. L., DiLavore, P. C., et al. (2000). The autism diagnostic observation schedule-generic: A standard measure of social and communication deficits associated with the spectrum of autism. Journal of Autism and Developmental Disorders, 30(3), 205-223. doi: 10.1023/A:1005592401947.

Lord, C., Rutter, M., \& Le Couteur, A. (1994). Autism diagnostic interview-revised: A revised version of a diagnostic interview for caregivers of individuals with possible pervasive developmental disorders. Journal of Autism and Developmental Disorders, 24(5), 659-685. doi:10.1007/BF02172145.

Ludemann, N., Clement, A., Hans, V. H., Leschik, J., Behl, C., \& Brandt, R. (2005). O-glycosylation of the tail domain of neurofilament protein $\mathrm{M}$ in human neurons and in spinal cord tissue of a rat model of amyotrophic lateral sclerosis (ALS). The Journal of Biological Chemistry, 280(36), 31648-31658. doi: 10.1074/jbc.M504395200.

Marshall, C. R., Noor, A., Vincent, J. B., Lionel, A. C., Skaug, J., et al. (2008). Structural variation of chromosomes in autism spectrum disorder. American Journal of Human Genetics, 82(2), 477-488. doi:10.1016/j.ajhg.2007.12.009.

Myers, A. J., Gibbs, J. R., Webster, J. A., Rohrer, K., Zhao, A., Marlowe, L., et al. (2007). A survey of genetic human cortical gene expression. Nature Genetics, 39(12), 1494-1499. doi: 10.1038/ng.2007.16.

Nurmi, E. L., Amin, T., Olson, L. M., Jacobs, M. M., McCauley, J. L., Lam, A. Y., et al. (2003). Dense linkage disequilibrium mapping in the 15q11-q13 maternal expression domain yields evidence for association in autism. Molecular Psychiatry, 8(6), 624-634, 570. 
Papanikolaou, K., Paliokosta, E., Gyftodimou, J., Kolaitis, G., Vgenopoulou, S., Sarri, C., et al. (2006). A case of partial trisomy of chromosome 8p associated with autism. Journal of Autism and Developmental Disorders, 36(5), 705-709. doi:10.1007/s10803006-0104-3.

Persico, A. M., \& Bourgeron, T. (2006). Searching for ways out of the autism maze: genetic, epigenetic and environmental clues. Trends in Neurosciences, 29(7), 349-358. doi:10.1016/j.tins. 2006.05.010.

Ravelli, R. B., Gigant, B., Curmi, P. A., Jourdain, I., Lachkar, S., Sobel, A., et al. (2004). Insight into tubulin regulation from a complex with colchicine and a stathmin-like domain. Nature, 428(6979), 198-202. doi:10.1038/nature02393.

Rutter, M., Le Couteur, A., \& Lord, C. (2003). Manual autism diagnostic interview-revised. Los Angeles: WPS publishers: Western Psychological Services.

Schellenberg, G. D., Dawson, G., Sung, Y. J., Estes, A., Munson, J., Rosenthal, E., et al. (2006). Evidence for multiple loci from a genome scan of autism kindreds. Molecular Psychiatry, 11(11), 1049-1060.

Schopler, E., Reichler, R. J., Bashford, A., Lansing, M., \& Marcus, L. M. (1990). Individualized assessment and treatment for autistic and developmentally disabled children. In Psychoeducational Profile Revised (PEP-R) (Vol. I). Austin, TX: Pro-Ed.

Sparrow, S. S., Balla, D. A., Cicchetti, D. V., \& Doll, E. A. (1984). Vineland adaptive behavior scales: Interview edition, survey form manual. Circle Pines: Minn: American Guidance Service.
Sebat, J., Lakshmi, B., Malhotra, D., Troge, J., Lese-Martin, C., Walsh, T., et al. (2007). Strong association of de novo copy number mutations with autism. Science, 316(5823), 445-449. doi:10.1126/science.1138659.

Vissers, L. E., de Vries, B. B., Osoegawa, K., Janssen, I. M., Feuth, T., Choy, C. O., et al. (2003). Array-based comparative genomic hybridization for the genomewide detection of submicroscopic chromosomal abnormalities. American Journal of Human Genetics, 73(6), 1261-1270. doi:10.1086/379977.

Vorstman, J. A., Staal, W. G., van Daalen, E., van Engeland, H., Hochstenbach, P. F., \& Franke, L. (2006). Identification of novel autism candidate regions through analysis of reported cytogenetic abnormalities associated with autism. Molecular Psychiatry, 11(1), 1-18-28. doi:10.1038/sj.mp.4001781.

Yang, M. S., \& Gill, M. (2007). A review of gene linkage, association and expression studies in autism and an assessment of convergent evidence. International Journal of Developmental Neuroscience, 25(2), 69-85. doi:10.1016/j.ijdevneu.2006.12.002.

Zhao, X., Leotta, A., Kustanovich, V., Lajonchere, C., Geschwind, D. H., Law, K., et al. (2007). A unified genetic theory for sporadic and inherited autism. Proceedings of the National Academy of Sciences of the United States of America, 104(31), 12831-12836. doi:10.1073/pnas.0705803104. 